\title{
O PAPEL DA CONSTITUIÇÃO NA TUTELA DE BENS COMUNS: PROTEÇÃO AOS SABERES DAS COMUNIDADES INDÍGENAS BRASILEIRAS
}

\section{THE ROLE OF THE CONSTITUTION IN COMMON PROPERTY PROTECTION: THE PROTECTION OF THE INDIGENOUS KNOWLEDGE BRAZILIAN}

\author{
${ }^{1}$ Juliano Dos Santos Seger
}

\section{RESUMO}

Este ensaio tem por escopo analisar a realidade vivenciada pelas comunidades indígenas brasileiras, desde o primeiro contato com os colonizadores europeus, colocando em destaque o embate cultural que permeou este contato. A pesquisa pretende contribuir para o debate sobre a possibilidade de apropriação dos saberes indígenas e sua proteção pelo direito de propriedade intelectual, apontando os óbices que o direito à cultura representa a essa prática que, na atualidade, tem ocorrido clandestinamente por meio da biopirataria. Nesse contexto, serão analisadas as disposições normativas da ordem internacional, especialmente as emanadas da Convenção da Diversidade Biológica e da Organização Mundial do Comércio, para ressaltar o papel da Constituição Federal de 1988 na tutela dos bens comuns, no caso, a diversidade cultural das comunidades indígenas do Brasil.

Palavras-chave: Direitos fundamentais, Cultura, Propriedade intelectual, Saberes indígenas

\begin{abstract}
This test is scope to analyze the reality experienced by Brazilian indigenous communities, from the first contact with European settlers, featured in putting the cultural clash that permeated this contact. The research aims to contribute to the debate on the possibility of appropriation of indigenous knowledge and its protection by intellectual property rights, pointing out the obstacles that the right to culture is this practice that, at present, there has been smuggled through biopiracy. In this context, the rules and regulations of the international order, especially those emanating from the Convention on Biological Diversity and the World Trade Organization will be analyzed, to highlight the role of the Federal Constitution of 1988 in the protection of common goods, in this case, the cultural diversity of communities Indians of Brazil.
\end{abstract}

Keywords: Fundamental rights, Culture, Intellectual property, Indigenous knowledge

\footnotetext{
${ }^{1}$ Mestre em Direito pela Universidade do Oeste de Santa Catarina - UNOESC, Joaçaba, Santa Catarina, (Brasil). Professor de Direito Penal e Criminologia, no Curso de Graduação em Direito da UNOESC, Campus Chapecó/SC. E-mail: julianoseger@mp.rs.gov.br
} 


\section{CONSIDERAÇÕES INICIAIS}

O estudo desenvolvido neste ensaio tem por objeto a temática da tutela dos conhecimentos tradicionais associados à biodiversidade, em razão de sua relevância no cenário dos direitos fundamentais da contemporaneidade. A problemática central consiste na possibilidade de apropriação dos saberes das comunidades indígenas para uso na atividade industrial e mercantil, diante dos contornos de proteção estabelecidos pela Constituição Federal de 1988 aos bens de natureza comum.

Os proveitos econômicos que podem ser extraídos dos conhecimentos tradicionais associados, com seu uso na atividade bioindustrial, colocam o assunto na pauta do direito internacional, num embate de escala global que traz à discussão a proteção jurídica aos bens comuns, especialmente a cultura das comunidades indígenas, frente às investidas expropriatórias da bioindústria transnacional, interessada na exclusividade de exploração econômica conferida pelo direito de propriedade intelectual.

A estruturação do texto, pautada pelo método dialético, buscará primeiramente reconstruir a realidade vivenciada pelas comunidades nativas brasileiras, revelando sua forma integrada de convivência social e interação com a natureza, em contraponto à cultura ocidental, individualista e fragmentada, que insiste em levar adiante seu movimento de hegemonização cultural, intensificado no atual cenário globalizado em que se interrelacionam países centrais e periféricos.

A parte inaugural, portanto, tem por objeto a demonstração das bases desse embate. A conceituação dos saberes indígenas e sua inserção no complexo cultural das comunidades originárias do Brasil ganha complemento com a ilustração das constantes investidas de expropriação das terras e recursos naturais, ao longo de mais de cinco séculos de colonização, para depois revelar uma das facetas mais recentes do neocolonialismo, a biopirataria voltada ao aspecto imaterial dos conhecimentos tradicionais associados.

A parte final dedica-se à discussão de escala global entre países centrais e periféricos, visitando os âmbitos da Convenção sobre Diversidade Biológica e da Organização Mundial do Comércio para, ao posicionar o debate no contexto da ordem jurídica internacional, desenvolver uma reflexão sobre o papel da Constituição da República Federativa do Brasil de 1988 na tutela dos bens comuns envolvidos, isto é, na proteção à cultura das comunidades indígenas brasileiras. 


\section{SABERES INDÍGENAS NOS CONTEXTOS DO VELHO E DO NOVO COLONIALISMO}

A primeira parte do ensaio pretende construir o conceito de saberes indígenas, em compasso com um resgate da realidade vivenciada pelas comunidades originárias do Brasil, desde a fase inicial do primeiro contato com os colonizadores até a contemporaneidade, num discurso que terá como eixo o embate cultural subjacente ao encontro das sociedades indígenas e europeias, com realce das formas distintas de conviver em sociedade e interagir com a natureza.

Ao construir o conceito de cultura, Thais Luzia Colaço (2011) remete suas origens ao vocábulo francês civilization e ao germânico kultur, utilizados para denominar, respectivamente, as realizações materiais de uma comunidade e os aspectos espirituais de um povo. A autora também destaca a síntese de Edward Tylor, assentada no vocábulo inglês culture, que congloba todas as possibilidades de realização humana, num complexo mais amplo que engloba conhecimentos, crenças, arte, moral, leis, costumes ou qualquer outra capacidade ou hábitos adquiridos pelo homem como membro de uma sociedade.

Na linha dessa concepção ampla de cultura, o estudo buscará pontuar os traços distintivos das formas socioculturais indígenas, em contraponto com as ocidentais, e evidenciar a maneira como a colonização colocou as comunidades indígenas em condição de vulnerabilidade e inferioridade frente ao movimento colonizador que, além da expropriação de terras e recursos naturais, andou perto de alcançar o desiderato de hegemonização cultural, na medida em que quase suplantou a cultura das comunidades indígenas brasileiras.

\subsection{Conceito Socioambiental dos Saberes Indígenas}

As teorias sobre as origens dos povos ameríndios ora atribuem-nas a uma migração terrestre vinda do nordeste asiático, ora a uma passagem por mar, mas existe certo consenso nas estimativas que demarcam em pelo menos 12 mil anos a temporalidade do povoamento do território brasileiro. Contudo, segundo Cunha (2012), o Brasil indígena de hoje se constitui apenas de fragmentos de um tecido social cuja trama, muito mais complexa e abrangente, provavelmente tenha recoberto a integridade do território, agora mais presente, sobretudo, na própria relação dos homens com a natureza.

Os saberes indígenas podem ser compreendidos como o aporte imaterial dessa relação entre homem e natureza, conservado pelo que restou da teia social que ocupava o território brasileiro antes da chegada dos colonizadores. Albergam-se no complexo dos denominados conhecimentos tradicionais associados à biodiversidade, que também abrangem 
conhecimentos de outras populações tradicionais; porém, com os diferenciais de ascendência pré-colombiana das populações e de conservação de línguas próprias.

Os atributos mais específicos dos saberes indígenas, portanto, estão relacionados com a temporalidade milenar a que se remete sua ancestralidade, bem como às línguas conservadas ao longo desse sucessivo elo de gerações. Não obstante, afora esses componentes especiais, apresentam-se características subjetivas e objetivas comuns às presentes em outras populações que cultivam conhecimentos tradicionais associados, identificadas com a forma coletiva de tradição e com o conteúdo vinculado à natureza.

A sabedoria indígena se qualifica como tradicional porque, subjetivamente, tem sua construção no seio da comunidade, de forma coletiva. O próprio sentimento de pertença étnica do índio em relação ao seu grupo social faz com que o indivíduo não se veja como tal, mas como parte integrante da comunidade, em que se transmitem noções ancestrais das gerações passadas, ao mesmo tempo em que se compartilham informações e vivências contemporâneas, transmitidas às gerações vindouras. Assim, assegura-se sua perpetuação.

A associação à biodiversidade, com viés mais objetivo, coloca em relevo a conexão que as comunidades indígenas mantêm com o ambiente, evidenciando um conteúdo estreitamente relacionado aos recursos naturais disponíveis nos espaços ocupados pelo grupo social. Essa forma integrada de contato com a natureza tem como característica o respeito aos seus ciclos, por meio da utilização sustentável dos recursos, que tem permitido a milenar continuidade da reprodução biológica e cultural das populações indígenas.

O histórico de baixo impacto ambiental, a forma equitativa de organização social e o interesse pelo território explorado pelo grupo, bem como dos traços culturais seletivamente reafirmados e reelaborados, na concepção de Santilli (2005), são fatores importantes no contex to dos conhecimentos tradicionais associados, que também destaca a relativa simbiose do grupo com o ambiente, circunstanciada por profundo conhecimento da natureza e seus ciclos e pela noção de território ou espaço onde se reproduzem socioeconomicamente.

$\mathrm{Na}$ verdade, a sabedoria indígena confunde-se com o patrimônio cultural das comunidades, que agrega noções ancestrais e experiências contemporâneas, a que se somarão as vivências das próximas gerações, num elo de perpetuação das populações. Trata-se de um jeito de viver que se assemelha aos postulados da visão sistêmica da vida, que visualizada o homem, a sociedade e a natureza de forma integrada, em convívio sustentável com a fauna e a flora dos ambientes ocupados. 
A leitura socioambiental do conceito dos conhecimentos tradicionais associados, aqui aos saberes indígenas, conjuga o elemento temporal milenar da ascendência indígena ao elemento linguístico próprio, além de englobar a forma tradicional de transmissão, no seio da coletividade, ao longo de sucessivas gerações. Dessa forma, reúne-se um conjunto de noções ancestrais e vivências contemporâneas que emergem da estreita vinculação dos elementos humano e social na interação com os recursos da biodiversidade.

\subsection{O Movimento de Colonização da Modernidade}

O contato inicial das comunidades indígenas com os colonizadores europeus remonta ao marco histórico do Descobrimento do Brasil, datado em 21 de abril de 1500. Santos Filho (2006) relembra que os integrantes da expedição portuguesa, em torno de mil e quinhentos homens, avistaram terra firme nessa data histórica, quando Pedro Álvares Cabral batizou o monte Pascoal, bem como a terra onde encravado, Vera Cruz. O que ocorreu depois de o Rei Manuel I, de Portugal, rebatizá-la como terra Santa Cruz merece um breve relato.

A partir da "descoberta”, desencadeou-se um complexo movimento de colonização, mais evidente na invasão territorial e na subjugação política das populações originárias ao poder central da Coroa portuguesa, mas que também apresenta repercussões religiosas, econômicas e socioculturais importantes, entre as quais se destaca o processo de aculturação imposto pela metrópole aos habitantes da colônia, fazendo ruir um mosaico incalculável de culturas e línguas próprias das diversificadas comunidades indígenas.

$\mathrm{O}$ vértice desse conflito bem pode ser encontrado nos postulados do antropocentrismo. Para Rêgo (2012), a filosofia ortodoxa judaico-cristã externa a visão antropocêntrica na passagem do Gênesis que conclama o homem a povoar a terra, subjugá-la e dominar os outros seres vivos. A ciência moderna visualiza a natureza como objeto do conhecimento empíricoracional, que devolveria ao homem o domínio sobre a criação; e, ao propor a separação entre homem e natureza, coloca o próprio Deus como entidade transcendente, externa à Criação. Com isso, a busca de novas e mais poderosas formas de controle e utilização da natureza, com fins utilitários e comerciais, tornou-se o maior sonho e o tema central da idade moderna.

A relação da metrópole com a colônia e seus habitantes originários revela a irradiação do ideal de dominação humana sobre a natureza, sobre a sociedade existente antes da colonização e sobre os próprios seres humanos envolvidos. A concretização desse ideal de apoderar-se de tudo quanto possível demandou a atuação em várias frentes, conglobando 
questões religiosas, políticas, sociais e, quiçá mais do que tudo isso, interesses econômicos inerentes ao novo sistema capitalista que emergia na época da virada da modernidade.

A contribuição religiosa para o processo colonizador consta das Bulas Romanus Pontifex e Inter Arcana, editadas pelos Papas Nicolau V e Clemente VII, respectivamente, nos anos de 1454 e 1529. Gomes (2012) destaca que a primeira, como num "prenúncio", havia garantido a Portugal o direito de conquistar novas terras, de bárbaros ou de infiéis, e submeter seus povos à servidão pelo uso da guerra, ao passo que a segunda sacramentou que as nações bárbaras deveriam vir ao conhecimento de Deus não só por editos e admonições, mas, se necessário, também pela força e pelas armas, a fim de que suas almas pudessem participar do reino do céu.

No entanto, a proliferação da fé cristã parece não ser o único objetivo. Além de possibilitar que se angariassem novos fiéis, a colonização conseguia agregar também os interesses econômicos das principais classes sociais da época. Aos agricultores, possibilitavase incrementar sua riqueza fisiocrata com o aumento das áreas agricultáveis; aos comerciantes, a ampliação de suas vias de comércio; aos industriais, surgiram novas fontes de matérias primas. Enfim, a influência econômica apresentava sua parcela de importância.

A Europa, na época, vivenciava a passagem do modelo econômico feudalista do medievo, autossuficiente e de caráter doméstico, para a formatação econômica capitalista da modernidade. Para Huberman (1977), na nova lógica mercantilista, a acumulação de capital transformou o dinheiro inativo, fixo e móvel em capital ativo, vivo e fluído, e a atividade comercial desafiava a expansão para novos mercados. O comércio em expansão rapidamente fez despontar o crescimento da riqueza em capital em relação ao da riqueza em terras.

Em certa medida, a própria descoberta do novo mundo encontra suas origens no ideal econômico-expansionista europeu da virada moderna, cujas grandes navegações, destinadas à ampliação do comércio, também descortinaram novas possibilidades para a expansão das fronteiras agrícolas, experimentada no Velho Continente três séculos antes, abrindo novos horizontes industriais e comerciais com a colônia, efetiva fornecedora de matéria prima e potencial consumidora de produtos manufaturados.

O ideário antropocêntrico se irradiava nas diferentes áreas, tendo como vértice os avanços das ciências naturais e a pretensa dominação exercida pelo homem sobre as forças da natureza, em decorrência do instrumental do método científico. Os colonizadores pioneiros, movidos por esse pensamento em ascensão, tinham a missão de conquistar as terras da colônia 
e desbravar seus recursos naturais, revelando muito bem a visão do homem como centro do universo e senhor da natureza.

Contudo, ao se depararem com os habitantes originários da colônia, os portugueses se viram diante de uma forma diferenciada de sociedade, com hábitos também diversos dos seus. Neste contraste de trejeitos, as inevitáveis comparações resultaram naquilo que, mais tarde, o pensamento antropológico denominaria evolucionismo unilinear. Como explica Barreto (2006), trata-se da teoria segundo a qual a cultura se desenvolve com certa uniformidade, tornando aceitável pressupor que cada sociedade percorresse as mesmas etapas evolutivas, com hierarquia de estádios.

A suposta escada hierárquica reservou o degrau inferior aos povos nativos, vistos como formas primitivas de sociedade. Assim, não bastasse o fato de serem desapossados de suas terras, os índios foram subjugados e forçados a servir na atividade econômica, na condição de escravos, sem qualquer consideração à sua condição de ser humano. Eis a lógica de dominação que permeou o contato entre indígenas e colonizadores, também presente no massacre bélico impostos a pretexto de catequizá-los e convertê-los ao cristianismo.

A economia colonial bem ilustra esse cenário. Furtado (1982) relata que, após curto período de escambo, a principal atividade econômica passou a ser a produção de açúcar; todavia, paralelamente, o espírito que movia o colonizador também conduziu a outra atividade: a captura e o comércio de índios, que constituiu a primeira atividade estável dos grupos de população não dedicados à indústria açucareira. A escravidão indígena, portanto, possibilitou a subsistência dos núcleos populacionais de regiões que não se transformaram em produtoras de açúcar.

Esse processo de apresamento destinado a recrutar mão de obra nativa para a colonização causou, na visão de Ribeiro (1995), um genocídio de proporções gigantescas, legitimado pelo poder central, já que o Rei decretava a legalidade do cativeiro de índios aprisionados em guerras justas. Contudo, aqueles capturados eram apenas uma fração da tribo avassalada, pois muitos morriam na luta pela própria liberdade, fugiam nos caminhos ou morriam de maus-tratos, de revolta ou de raiva no cativeiro.

Nessas condições, enquanto o avanço sobre as terras e a expropriação econômica dos recursos naturais são movimentos mais sensíveis, correu veladamente o maior golpe que as comunidades indígenas sofreram e, ao que parece, ainda têm sofrido. Trata-se do movimento de homogeneização cultural identificado com o paradigma da aculturação, que apregoa a 
eventual e inevitável extinção das culturas e das sociedades indígenas diante da inexorável força de expansão da civilização ocidental. (GOMES, 2012)

O paradigma fundado em tais premissas enuncia a ideia de que o índio, individual ou coletivamente, deve passar por estágios de evolução cultural até chegar ao padrão civilizado europeu. Consoante Barreto (2006), o pensamento evolucionista unilinear, assim proposto, defende que, conforme aumente a semelhança com o nível de civilização reputado mais evoluído, distanciando-se daquele estágio dito inferior, os índios galgariam uma escala hierárquica na qual se colocam as categorias de isolados, em vias de integração e integrados.

Os reflexos jurídicos desse pensamento estão estampados na legislação indigenista vigente desde o Descobrimento, voltada exclusivamente aos próprios interesses da Coroa portuguesa, para quem o índio sempre foi considerado um ser inferior. ${ }^{1}$ Talvez por isso, as comunidades indígenas, cujas formas de interação social dão corpo ao denominado direito indígena, de caráter oral e costumeiro, passaram ao largo da formulação da política integradora e do aporte jurídico imposto desde os primeiros tempos do período colonial.

As leis elaboradas pelos jurisconsultos da Corte, vez ou outra orientados pela doutrina do direito natural dos povos não cristãos, resultaram em lampejos de reconhecimento da soberania indígena frente aos constantes atos de legitimação da escravidão. Todavia, como ressalta Gomes (2012), o padrão português de políticas indigenistas moldava-se pela lógica da conquista e colonização, bem como pela necessidade de defender o território e angariar mão de obra, sempre conservando o propósito de dominação absoluta.

Seria impossível inventariar tudo o que se perdeu com o massacre da assimilação, mas os dados demográficos, que revelam a redução populacional das comunidades indígenas, podem dar uma ideia das perdas em diversidade ocorridas no contexto sociocultural dessas populações. Ribeiro (1995) e Gomes (2012) referem que as estimativas relativas à demografia do momento inicial da invasão portuguesa informam que, naquela época, haveria no Brasil uma população de aproximadamente cinco milhões de índios.

Barbosa (2001) menciona que, no final da década de 1980, restavam apenas 250 mil índios, aproximadamente, distribuídos em cerca de 200 comunidades, com a seguinte demografia: 80 etnias tinham até 200 integrantes, 45 etnias compostas por 200 a 500 indivíduos e 35 etnias com população entre mil e cinco mil; Guajajaras, Potiguaras,

\footnotetext{
${ }^{1}$ Manuela Carneiro Cunha destaca, entretanto, que o primeiro século da colonização dividiu duas imagens formadas em torno da figura do índio: a francesa, de viajante, que o exaltava; a ibérica, de colono, que o depreciava. (2010, p. 28-50)
} 
Xavantes e Yanomamis tinham entre cinco mil a dez mil membros, ao passo que Terenas, Makuxis, Ticunas e Kaingangs somavam entre dez mil e vinte mil. Apenas o povo Guarani passava de vinte mil.

Atualmente, segundo dados do Censo Demográfico 2010, realizado pelo Instituto Brasileiro de Geografia e Estatística (IBGE), pelo menos 817.963 brasileiros declararam origem indígena, sendo 502.783 com residência no meio rural e 315.180 no meio urbano. ${ }^{2}$ A Fundação Nacional do Índio (FUNAI), por sua vez, estima que existam 572 mil índios residentes na área rural, dos quais 517 mil estariam alocadas no interior de reservas indígenas reconhecidas. $^{3}$

Esses dados demonstram que, não obstante a constante opressão assimiladora, certas comunidades indígenas brasileiras resistiram ao paradigma da integração, conservando suas sociedades tradicionais. Ademais, ao resistirem aos avanços sobre as terras tradicionalmente ocupadas, seus recursos naturais e, principalmente, sua cultura, conservaram o patrimônio imaterial de suas memórias ancestrais, cunhadas de geração em geração desde remotos tempos pré-colombianos.

\subsection{O Movimento de Neocolonização da Contemporaneidade}

Na atual economia globalizada, em que, como referem Iacomini (2009) e Lima (2013), até mesmo a inimaginável venda de sangue de comunidades indígenas se anuncia na internet, emerge a necessidade de um diálogo sério sobre o papel das Constituições na proteção de bens comuns, entre os quais se incluem os saberes milenares das comunidades indígenas brasileiras. Afinal, sem qualquer medo de errar, afirma-se que o ideal de lucro, que permeia a atividade econômica, ignora a fronteira dos direitos fundamentais.

A nova página do movimento colonizador, tal como se desenha no início do terceiro milênio, de certa forma, migra a relação de dominação que sempre permeou a interação entre países centrais, de maiores recursos industriais e tecnologia, e os países periféricos, onde se sobressai a riqueza da sociobiodiversidade. Agora, intensificou-se o interesse por recursos genéticos e conhecimentos tradicionais associados à biodiversidade, especialmente os saberes indígenas, no novo contexto de colonização centro-periférica.

Isso talvez se explique porque o conhecimento, de forma geral, sempre interessou à economia. A própria teoria do desenvolvimento econômico destaca, paralelamente a variáveis

\footnotetext{
${ }^{2}$ Disponível em: <http://indigenas.ibge.gov.br/graficos-e-tabelas-2>. Acesso em: 25 out. 2014.

${ }^{3}$ Disponível em: <http://www.funai.gov.br/index.php/indios-no-brasil/o-brasil-indigena-ibge>. Acesso em: 12 jan. 2015.
} 
histórico-culturais, certas forças fundamentais para o processo de crescimento, relacionadas à dimensão e organização do sistema produtivo básico de um país: crescimento demográfico, recursos naturais, acumulação de capital, aumento na escala ou na especialização da produção e progresso tecnológico (GILL, 1972).

Richard T. Gill (1972) esclarece que o crescimento moderno não pode ser encarado como mero aumento de fatores de produção, senão como uma mudança radical e contínua de seu modo de utilização, em que se sobressaem habilidades, qualidades e atitudes dos seres humanos envolvidos no moderno desenvolvimento, como diferenciais capazes de dar-lhe forma e direção. Sem olvidar a importância dos demais fatores, os elementos ligados ao aperfeiçoamento da organização e da tecnologia são colocados em redobrado relevo, diante do potencial quantitativo e qualitativo que agregam ao crescimento.

Nesse contexto, emerge a atividade de bioprospecção como meio de detecção do valor econômico da matéria-prima biodiversidade, utilizando e aproveitando o conhecimento tradicional dos povos autóctones sobre o uso de plantas, animais e microorganismos para favorecer o crescimento econômico, em especial nas áreas agrícola, farmacêutica e cosmética. A indústria farmacêutica, no exemplo citado por Rêgo (2012), visualiza as florestas em função de seu valor como material potencial para elementos medicinais e o conhecimento indígena como chave para a descoberta dessas formas medicinais.

O cenário da pirataria biológica, portanto, envolve um complexo conflito entre biodiversidade e interesses econômicos, colocando a própria cultura indígena na mira da indústria da biotecnologia. Segundo Barbieri (2014), Iacomini (2009) e Lima (2013), a origem do termo biopirataria remonta ao ano de 1993, quando a organização não governamental RAFI, atual ETC-Group, lançou o alerta de que recursos naturais e conhecimentos tradicionais indígenas passaram a ser alvo de apropriação e patenteamento por grandes corporações internacionais e instituições científicas.

A prática da biopirataria, inicialmente, até causa certa estranheza, pois parece um tanto incompreensível que países centrais, intitulados desenvolvidos e avançados, venham a se tornar aprendizes dos povos periféricos para agregar a sabedoria dos trópicos na atividade industrial. Mas essa perplexidade desaparece assim que analisados os benefícios econômicos que os conhecimentos tradicionais associados podem render na atividade bioindustrial, ainda mais considerando os lucros que o direito de propriedade intelectual pode assegurar. 
Barbieri (2014) ressalta que três quartos dos princípios ativos atualmente isolados de plantas superiores - cerca de 80 dos 120 catalogados - possuem utilidades que foram identificadas por sistemas tradicionais. Menos de doze são sintetizados por modificações químicas simples, ao passo que o restante é extraído diretamente de plantas e depois purificado. A eficiência do reconhecimento das propriedades medicinais de plantas, com os conhecimentos tradicionais, aumenta em mais de $400 \%$ !

Até mesmo os adeptos da teoria econômica marginal da utilidade ${ }^{4}$ - segundo a qual os meios de produção teriam menor importância que as necessidades de consumo, de tal forma que as utilidades de mercado se sobreporiam aos custos produtivos - teriam de admitir que o acesso aos saberes indígenas, ao diminuir tempo e custo de pesquisas da atividade bioindustrial, potencializa o avanço tecnológico e aumenta a rentabilidade, constituindo fator econômico de grande importância.

Enfim, na área da atual indústria da biotecnologia, o conjunto de saberes de caráter milenar das comunidades indígenas sobre a diversidade biológica, por apresentar tamanha qualidade empírica que permite encurtar o tempo das pesquisas, descortina a possibilidade, sedutora aos olhos do capital, de redução de custos de produção. Como isso significa maior lucratividade, fica muito evidente o porquê da intensificação da captação de saberes junto às comunidades indígenas brasileiras.

O Brasil se destaca por possuir a maior variedade biológica do mundo, reunindo mais de vinte por cento do número total de espécies existentes, segundo dados do Ministério do Meio Ambiente. ${ }^{5}$ Mais do que isso, a maior biodiversidade do planeta ainda vem circunstanciada por um vasto mosaico de populações que agregam aos recursos naturais um imensurável complexo de conhecimentos tradicionais associados. Nesse contexto socioambiental diversificado, a biopirataria se orienta, de forma interligada, em várias frentes.

A expropriação ora se direciona aos recursos naturais tangíveis, ora aos intangíveis conhecimentos tradicionais associados. Segundo Iacomini (2009), abrange tanto a apropriação de plantas, animais e conhecimentos como amostras de tecidos orgânicos, genes e células que tenham potencial de exploração econômica. A logística da atividade dos biopiratas caracteriza-se pelo contrabando dos recursos naturais e pela aprendizagem dos conhecimentos tradicionais, para posterior registro individual.

\footnotetext{
${ }^{4}$ A teoria foi desenvolvida, independentemente, por Stanley Jevons (Inglaterra, 1871), Karl Menger (Áustria, 1871) e Léon Walras (Suíça, 1874). (HUBERMAN, 1977)

${ }^{5}$ Disponível em: <http://www.mma.gov.br/biodiversidade/biodiversidade-brasileira >. Acesso em: 10 fev. 2015.
} 
A importância da expropriação dos recursos tangíveis da natureza tem sido bem mais comum, como bem evidencia a própria quantidade de casos levantados pela literatura. ${ }^{6}$ Não obstante, dados os propósitos do presente estudo, será analisada apenas a biopirataria direcionada ao patrimônio intangível das comunidades indígenas, seu conjunto de saberes vinculados à biodiversidade, com ilustração no caso Ayahuasca ou Cipó da Alma, cuja repercussão, consoante Rêgo (2012), foi extremamente significativa.

Barbieri (2014) relembra que a planta Banisteriopsis Caapi tem sido utilizada por comunidades indígenas amazônicas, desde tempos ancestrais, para produção de uma bebida utilizada em rituais ligados à espiritualidade, como instrumento de cura, tratamento e diagnóstico de doenças, além de integrar o cerimonial de encontro com espíritos e adivinhação do futuro. No entanto, em 1986, a United States Patentand Trademark Office (USPTO) concedeu a Loren Miller o direito de propriedade intelectual da bebida indígena, por ele intitulada "Da Vine".

A autora ainda menciona a mobilização promovida pela Coordenação das Organizações Indígenas da Bacia Amazônica (COICA), que acabou levando o Centro para Lei Internacional Ambiental (CIEL) a requerer a anulação da patente perante o escritório estadunidense de Patentes e Marcas da Agência de Comércio Americano, com o acolhimento do pedido e respectiva anulação, em 1999. Mesmo assim, a patente ainda teve revalidação, após reapresentação, entre 2001 e 2003.

Trata-se de um exemplo que revela como a expertise mercantil de alguém estranho à comunidade indígena possibilita a aprendizagem de determinado saber milenar para, depois de revesti-lo pelo manto do direito de propriedade intelectual, inseri-lo na atividade industrial. Essa prática especializada transforma os saberes indígenas em fator econômico, com o detalhe de reverter os proveitos exclusivamente em favor do titular do direito de propriedade intelectual e suprimir a identidade do autor original da ideia, negando-lhe os proveitos.

Assim, desfecha-se a reconstrução proposta para este primeiro tópico, demonstrando o fluxo de dominação e subjugação que a colonização e a neocolonização têm imposto às comunidades indígenas brasileiras, seja pela expropriação de suas terras e riquezas naturais, seja pela captação clandestina de seu intangível conhecimento sobre a biodiversidade.

\footnotetext{
${ }^{6}$ Destacam-se alguns casos relevantes de biopirataria: Cupuaçu, Açaí, Andiroba, Copaíba, Vacina do Sapo, Espinheira Santa, Jaborandi, Jambu, Veneno da Jararaca e Pau-rosa (BARBIERI, 2014), bem como Seringueira e Murumuru (LIMA, 2013). Outros casos constam do site da ONG Amazonlink (http://www.amazonlink.org/biopirataria/).
} 
Assentam-se, assim, as bases para o debate acerca do papel da Constituição Federal de 1988 na tutela dos interesses dessa minoria étnica que integra o povo brasileiro.

\section{A TUTELA CONSTITUCIONAL DOS BENS COMUNS: PROTEÇÃO À CULTURA DAS COMUNIDADES INDÍGENAS}

A reconstrução da realidade das comunidades indígenas, ao longo de um processo de colonização que perdura mais de cinco séculos, permite identificar um conflito de interesses, notadamente econômicos, em torno não só das terras e dos recursos naturais tangíveis dessas comunidades, mas também em relação ao complexo imaterial dos saberes milenares vinculados à biodiversidade, cujas repercussões na ordem jurídica internacional são doravante analisadas.

A Declaração Universal dos Direitos Humanos da Organização das Nações Unidas (ONU) de 1948, segundo Santos Filho (2006), lançou as bases do sistema jurídico internacional de tutela dos direitos humanos, proclamando direitos civis e políticos, bem como direitos econômicos, sociais e culturais, entre os quais se incluem os direitos das comunidades indígenas - de titularidade coletiva: povo, família, nação e etnia - relacionados à proteção da dignidade humana, ao meio ambiente, ao desenvolvimento, à paz e ao patrimônio comum da humanidade.

O sistema especial de proteção dos direitos humanos relacionado aos índios, que teve como primeiro diploma a Convenção 107 da Organização Internacional do Trabalho (OIT), de 1957, ganhou novos ares em 1989, com a Convenção Sobre Povos Indígenas e Tribais em Países Independentes, a Convenção 169 da OIT, que revisou aquele texto integracionista e assegurou o direito das comunidades indígenas viverem e se desenvolverem como povos diferenciados, em conformidade com seus padrões próprios. (SANTOS FILHO, 2006)

E a Declaração das Nações Unidas sobre os Direitos dos Povos Indígenas (2007) reservou aos povos indígenas o direito de manutenção, controle, proteção e desenvolvimento de seu patrimônio cultural, seus conhecimentos tradicionais, suas expressões culturais tradicionais e as manifestações de suas ciências, tecnologias e culturas, bem como de sua propriedade intelectual sobre o mencionado patrimônio cultural, seus conhecimentos tradicionais e suas expressões culturais tradicionais. Determinou aos Estados, ademais, que adotem medidas eficazes para reconhecer e proteger o exercício desses direitos, em conjunto com os povos indígenas: 
Artigo 31. 1. Os povos indígenas têm o direito de manter, controlar, proteger e desenvolver seu patrimônio cultural, seus conhecimentos tradicionais, suas expressões culturais tradicionais e as manifestações de suas ciências, tecnologias e culturas, compreendidos os recursos humanos e genéticos, as sementes, os medicamentos, o conhecimento das propriedades da fauna e da flora, as tradições orais, as literaturas, os desenhos, os esportes e jogos tradicionais e as artes visuais e interpretativas. Também têm o direito de manter, controlar, proteger e desenvolver sua propriedade intelectual sobre o mencionado patrimônio cultural, seus conhecimentos tradicionais e suas expressões culturais tradicionais. 2. Em conjunto com os povos indígenas, os Estados adotarão medidas eficazes para reconhecer e proteger o exercício desses direitos.

No entanto, países centrais e países periféricos ainda encontram um ponto de divergência quando se trata do assunto da apropriação dos saberes indígenas para fins industriais e mercantis, cuja superação perpassa questões éticas importantes. Trata-se, em última análise, da possibilidade de mercantilização da vida, a que se soma a negativa de reconhecimento da cultura e identidade das comunidades indígenas, na medida em que, ao dar como sua a criação de origem milenar, o titular do direito de propriedade intelectual sonega a verdadeira origem da sabedoria patenteada.

Rêgo (2012) ressaltada que a discussão entre o valor da natureza em relação ao homem polariza entendimentos bem distanciados, permeado por posicionamentos entre esses extremos. De um lado, entende-se que a natureza e cada ser vivo possui valor intrínseco, indistintamente, consoante a visão do biocentrismo; de outro, concebe-se a natureza como mero valor instrumental a serviço do homem, uma simples reserva de recursos a serem explorados, de acordo com o antropocentrismo, que coloca o homem como centro da natureza e do universo.

Às comunidades indígenas, quer parecer que o interesse primário consiste em dar continuidade ao seu modo de vida integrado social e ambientalmente, sem interferências externas que possam comprometer a perpetuação de suas sociedades. Porém, a isso se soma o interesse de obter o reconhecimento do complexo cultural consolidado em suas tradições, costumes, crenças e línguas, enfim, sua própria identidade, impedindo que supostos inventores apropriem-se da sabedoria indígena e proclamem-na como própria.

Já, aos detentores do vasto aparato bioindustrial e biotecnológico, obviamente interessa a tese de que o acesso aos conhecimentos dos índios não poderia sofrer obstáculos. Afinal, a inegável contribuição para o avanço das pesquisas, notadamente com redução de 
custos e tempo, poderia render à humanidade os proveitos decorrentes do desenvolvimento de novas tecnologias e produtos, ao passo que a titularidade da propriedade intelectual seria o prêmio aos responsáveis pela captação e uso dos saberes indígenas na atividade bioindustrial.

Aos países onde se encontram as comunidades indígenas, especialmente o Brasil, a tutela constitucional da cultura dos índios impede o acesso irrestrito aos seus saberes milenares, considerados patrimônio cultural nacional, para fins mercantis. Entretanto, o potencial desses saberes na economia não passe despercebido ao Estado brasileiro, porquanto o tema constitui pauta da cena política nacional e vem levantando questionamentos sobre o papel da Constituição na tutela dos bens comuns, em boa medida por seus reflexos econômicos.

Ao analisar a postura dos países desenvolvidos, em contraste com os países em desenvolvimento ou subdesenvolvidos, Pereira (2009) destaca que os primeiros, cujos agentes econômicos detêm tecnologias avançadas, possuem grande interesse em reforças os direitos de propriedade intelectual; já, os demais, estimam que poderia ser melhor copiar as invenções desenvolvidas alhures a pagar caro pela tecnologia estrangeira, colocando-se, consequentemente, em situação de permanente dependência.

$\mathrm{Na}$ órbita internacional dos conflitos que versam sobre recursos da biodiversidade, conhecimentos tradicionais associados e direito de propriedade intelectual, destaca-se inicialmente a orientação da Organização Mundial da Propriedade Intelectual (OMPI) no sentido de que as inovações baseadas em conhecimentos tradicionais associados podem receber proteção de patente, marca e indicações geográficas, bem como de segredo comercial ou informação confidencial, mas o próprio conhecimento, de raízes antigas e transmissão por via oral, não se encontra protegido pelos sistemas convencionais de propriedade intelectual. ${ }^{7}$

Vale destacar que, embora a OMPI não apresente normas consolidadas sobre da apropriação mercantil dos conhecimentos tradicionais associados, o tema não lhe parece totalmente estranho, porquanto sua estrutura institucional conta com o Comitê Intergovernamental sobre Propriedade Intelectual e Recursos Genéticos, Conhecimento Tradicional e Folclore. ${ }^{8}$ Ademais, em 2015, a instituição promoveu, na Austrália, o Seminário

\footnotetext{
${ }^{7}$ Disponível em: <http://www.wipo.int/tk/es/tk/>. Acesso em: 18 mai. 2015.

${ }^{8}$ Disponível em: < http://www.wipo.int/tk/es/>. Acesso em: 18 mai. 2015.
} 
sobre Propriedade Intelectual e Recursos Genéticos, Conhecimentos Tradicionais e Expressões Culturais Tradicionais: Experiências Regionais, Nacionais e Locais. ${ }^{9}$

No entanto, por ora, reafirma-se que persiste a lacuna normativa acerca da temática no âmbito da OMPI, e que essa omissão da instituição favorece a pilhagem do patrimônio imaterial das comunidades indígenas, na medida em que se reconhece o direito de propriedade intelectual a inventos nos quais incorporados conhecimentos tradicionais associados. Nesse contexto, passa-se ao exame das normas estabelecidas no âmbito da Convenção sobre Diversidade Biológica (CDB) e da Organização Mundial do Comércio (OMC).

\subsection{Convenção sobre Diversidade Biológica}

A Convenção sobre Diversidade Biológica se consolidou na Conferência das Nações Unidas sobre Meio Ambiente e Desenvolvimento (CNUMAD), no Rio de Janeiro, em 1992, contando com a ratificação de 188 países. Os principais objetivos desse instrumento convencional de tutela da biodiversidade são a conservação da diversidade biológica, a utilização sustentável de seus componentes e a repartição justa e equitativa dos benefícios derivados da utilização dos recursos genéticos.

Rêgo (2012) aponta como ponto crucial de divergência, no âmbito da CDB, a inclusão das biotecnologias como objeto do acordo. Brasil, Índia, China e outros países de rica biodiversidade exigem o acesso aos avanços em biotecnologia, com uso sustentável e partilha de benefícios, como condição para liberar o acesso à diversidade biológica encontrada em seus territórios, ao passo que os Estados Unidos e outros países ricos e com tecnologia de ponta rejeitam essa inclusão.

A autora ainda destaca que o Norte apregoa o discurso do acesso livre e universal à biodiversidade, formulado por países interessados em preservar a fonte de matéria-prima biológica concentrada nos trópicos do planeta, ao passo que o Sul defende o discurso que visualizada a diversidade biológica como patrimônio nacional dos países em desenvolvimento, interessados em assegurar a participação nos benefícios decorrentes do uso dos recursos genéticos frequentemente patenteados e comercializados pelos detentores da tecnologia avançada.

A Conferência das Partes de outubro de 2010 (COP-10) dedicou-se à discussão acerca do acesso ao patrimônio genético e aos conhecimentos tradicionais associados, em posse de

\footnotetext{
${ }^{9}$ Disponível em: <http://www.wipo.int/edocs/mdocs/tk/es/wipo_iptk_ge_15/wipo_iptk_ge_15_inf_1_prov_2.pdf>. Acesso em: 06 abr. 2015.
} 
comunidades indígenas e locais, resultando na elaboração do Protocolo de Nagoya (2010), que estabelece requisitos ao acesso, em conformidade com as leis nacionais e com consentimento prévio das populações tradicionais, resguardando-se sua participação nos benefícios, mediante condições mutuamente acordadas:

Artículo 7 - Acceso a conocimientos tradicionales asociados a recursos genéticos. De conformidad con las leyes nacionales, cada Parte adoptará medidas, según proceda, con miras a asegurar que se acceda a los conocimientos tradicionales asociados a recursos genéticos que están en posesión de comunidades indígenas y locales con el consentimiento fundamentado previo o la aprobación y participación de dichas comunidades indígenas y locales, y que se hayan establecido condiciones mutuamente acordadas.

O Brasil figura como signatário da $\mathrm{CDB}$, incorporada ao ordenamento jurídico pelo Decreto 2.159/1998 e ratificada pelo Decreto Legislativo 02/1994, do Congresso Nacional. Antes mesmo da elaboração do Protocolo de Nagoya, o Poder Executivo, por meio da Medida Provisória 2.186-16/2001, regulou a matéria do acesso ao patrimônio genético e aos conhecimentos tradicionais associados, com certa preocupação com a tutela da biodiversidade brasileira.

Este diploma, não obstante seu caráter provisório, tem assegurado alguma proteção do conhecimento das comunidades indígenas e das comunidades locais, associado ao patrimônio genético, reconhecendo-lhes o direito de decidir sobre o uso desses conhecimentos tradicionais e o direito à repartição justa e equitativa dos benefícios resultantes da exploração econômica de produto ou processo desenvolvido a partir de amostra de componente do patrimônio genético e de conhecimento tradicional associado.

O Protocolo de Nagoya foi apresentado ao Congresso Nacional do Brasil em 11 de junho de 2012 (MSC 245/2015), mas desde aquele mês se encontra em apreciação pela Comissão Especial formada para analisar a conveniência da ratificação. Não obstante, o Poder Legislativo brasileiro foi mais ágil ao aprovar o Projeto de Lei 7.735/2014, sancionado pelo Poder Executivo e transformado na Lei 13.123/2015, de 20 de maio deste ano, denominado Marco da Biodiversidade, com vigência prevista para 180 dias depois da publicação.

O Marco da Biodiversidade, ainda na fase de projeto, foi objeto de críticas (TOLEDO, 2015), diante das constatações de que o sistema abdica do consentimento prévio fundamentado e não prevê a partilha de benefícios em fases anteriores à comercialização do produto acabado; permite a isenção de partilha para pequenas empresas e institui uma alíquota 
única de $1 \%$ de royalty sobre a renda líquida do comércio de todos os produtos obtidos com a matéria-prima nacional, passível de redução a $0,1 \%$ para garantir competitividade às empresas; não exige que o trabalho de obtenção de produtos seja realizado em território nacional.

Nesse contexto, quer parecer que o movimento legislativo tendente a consolidar a CDB tem sofrido a oposição de interesses que, a que tudo indica, coadunam-se com os defendidos pela indústria da biotecnologia. Essa inferência se explica com a verificação de que freios foram colocados à ratificação do Protocolo de Nagoya, bem mais interessante para o Brasil, sonegando o aparato de tutela formado em torno pelos institutos do consentimento prévio, do acordo mútuo e da partilha de benefícios. Em vez disso, deu-se a facilitação do acesso aos recursos da biodiversidade e aos conhecimentos tradicionais associados.

As manobras legislativas em questão bem demonstram por que a CDB, aclamada como instrumento fundamental para conter a erosão da biodiversidade no planeta, tem enfrentado questionamentos acerca de sua efetividade, como destaca Rêgo (2012). A globalização e a chegada de novas biotecnologias abriram possibilidades e atraíram interesses internacionais, intensificando o acesso aos recursos da biodiversidade brasileira, reafirmando a costumeira acessibilidade sem controle e sem contrapartida dos países centrais em relação aos países dos trópicos.

Enfim, em meio às diversas disposições normativas consubstanciados no texto da CDB, depois reproduzidos no Protocolo de Nagoya, interessam sobremaneira ao presente estudo o consentimento prévio informado (Prior Informed Consent - PIC), os termos mutuamente acordados (Mutually Agreed Terms - MAT) e o acesso e repartição de benefícios (Access and Benefit Sharing - ABS), considerados instrumentos para a intermediação do acesso aos recursos genéticos e aos conhecimentos tradicionais associados. (COSTA, 2013)

A utilização desses mecanismos de diálogo e negociação entre as populações que cultivam tradicionalmente conhecimentos vinculados à diversidade biológica seria uma forma de superar a prática clandestina da biopirataria, revestindo essa realidade de juridicidade e maior controle. Contudo, a resistência capitaneada pela bioindústria bem reflete o conflito de interesses econômicos subjacente. Afinal, a persistir a desregulamentação, saem favorecidos aqueles que acessam os saberes sem necessidade de contrapartida.

\subsection{Organização Mundial do Comércio}


O Acordo sobre Aspectos da Propriedade Intelectual Relacionados ao Comércio ou TRIPS (Trade-Related Aspects of Intellectual Property Rights), figura como um dos acordos constitutivos da Organização Mundial do Comércio. Segundo Pereira (2009), o instrumento de regulação da propriedade intelectual foi aprovado na última rodada de negociações multilaterais do antigo Acordo Geral de Tarifas e Comércio ou GATT (General Agreement on Tariff and Trade), ocorrida entre 1986 e 1994, na denominada Rodada Uruguai.

Resultado de uma coalizão de empresas autointitulada Comitê da Propriedade Intelectual (IPC), o acordo arquitetado para proteger a propriedade intelectual contempla apenas os esforços inovadores individuais em laboratórios científicos. RÊGO (2012) coloca em evidência o fato de que, no acordo, os conhecimentos coletivos transmitidos de geração em geração são descartados, depois de colocados como estado da técnica, para permitir que as empresas da biotecnologia aproveitem-se dos saberes indígenas milenares, numa espécie de recolonização do Terceiro Mundo, o bioimperialismo.

Lima (2013) destaca que o artigo 27.3.b do TRIPS legitima a biopirataria, pois viabiliza a prática da apropriação indevida de componente da diversidade biológica, com a permissão do patenteamento de organismos vivos. Além disso, importantes divergências em relação à $\mathrm{CDB}$ são destacadas, quanto à soberania dos Estados em relação aos recursos biológicos de seus territórios, à diferença de objetivos entre os dois acordos e, ainda, à tutela dos conhecimentos tradicionais associados à biodiversidade, sequer cogitados no TRIPS.

Para Pereira (2009), o instituto da patente, inicialmente, tinha como objetivo o incentivo à criatividade; agora, possui fins econômicos de recompensa, por monopólios, aos investimentos em pesquisa, de certa forma mitigando os efeitos positivos primeiramente ressaltados. Nesse contexto, a possibilidade de usurpação da natureza e dos conhecimentos tradicionais associados fere a soberania e coloca, como influxo dessa expropriação, a imposição de condições socioambientais e a participação nos lucros.

Na visão da autora, faz-se necessário estabelecer regras diferentes conforme a situação socioeconômica de cada país, a fim de compensar as desigualdades, e não meramente regular o mercado, sem repercussões no bem-estar da sociedade. A cada país membro da OMC, portanto, caberá o papel de considerar os elementos de ordem econômica, social e ética que reflitam suas necessidades e interesses, a exemplo da quebra de patentes de medicamentos, no Brasil, para disponibilizar tratamento mais eficiente à população. 
Como o TRIPS, propositadamente ou não, apresenta lacuna a respeito do acesso aos conhecimentos tradicionais associados e da repartição justa e equitativa dos benefícios, franqueia a possibilidade de apropriação da sabedoria indígena e sua incorporação aos inventos, a que se confere proteção pelo direito individual de propriedade intelectual, sem necessidade de nenhuma contrapartida às populações tradicionais em cujos espaços socioculturais são constituídos os saberes.

Ademais, grande diferença paira na coercibilidade e dos dois instrumentos e, consequentemente, na eficácia de suas normas. Enquanto a CDB apresenta natureza jurídica soft law, com caráter declaratório que orienta a atuação futura dos Estados, o TRIPS possui natureza jurídica hard law, com previsão de sanção jurídica em caso de descumprimento. De acordo com Lima (2013), pois, o sistema jurídico internacional protege de forma mais eficaz os direitos de propriedade intelectual em relação aos conhecimentos tradicionais e aos direitos inerentes à preservação da diversidade biológica, dificultando a implementação da CDB.

Merecem destaque, também, as observações de Basso (2005) acerca de uma tendência da atualidade, qual seja, o resgate do bilateralismo existente antes do TRIPS, com o mesmo objetivo de aumentar a proteção ao direito de propriedade intelectual. Agora, porém, o novo bilateralismo orienta-se para a criação de fórum shifting, com outras alternativas, fora do sistema OMC/OMPI, que permitam desenvolver e implementar uma nova agenda e fixar novos padrões de proteção, sem as restrições e regulamentações da OMC.

A autora também destaca a nova tendência de coordenação das estratégias bilaterais e multilaterais de propriedade intelectual, com o propósito de não violar os acordos já celebrados no âmbito da OMC/OMPI, evitando disputas no Sistema de Solução de Controvérsias da OMC. Ademais, a manutenção do princípio do minimum standards nos acordos celebrados não implica revogação do anterior e, com isso, possibilita estabelecer padrões mais elevados de proteção.

Fora da multilateralidade do TRIPS, tem-se o esquema TRIPS-plus e TRIPS-extra, que se forma por negociações bilaterais, geralmente envolvendo um país industrializado e outro em desenvolvimento relativo, em que se determinam ou expandem direitos de propriedade intelectual, diretamente, por acordos específicos (Bilateral Intellectual Property Agreements), ou, indiretamente, por acordos diversos que incluem o reconhecimento de propriedade intelectual, como investimento. Ainda existe a forma regional e sub-regional de comércio, em que normalmente se insere um capítulo sobre direitos de propriedade intelectual. (BASSO, 2005) 
Enfim, a demonstração da evidente diferença de propósitos entre a CDB e o TRIPS, que se posicionam, respectivamente, nas trincheiras da preservação ambiental e da proteção comercial, e ainda com a renovação da estratégia de negociações bilaterais, regionais e subregionais em prol da proteção ao direito da propriedade intelectual, questiona-se o papel da Constituição brasileira, base do ordenamento jurídico interno, como um filtro dessa ordem jurídica internacional que polariza interesses de países centrais e periféricos.

\subsection{Papel da Constituição da República Federativa do Brasil de 1988 na tutela dos saberes indígenas}

O histórico constitucional brasileiro revela que o reconhecimento dos direitos das comunidades indígenas se mostra recente, afinal, a Constituição Política do Império do Brasil de 1824 e a Constituição da República dos Estados Unidos do Brasil de 1891 não contemplaram nenhuma disposição a respeito, como relembra Santos Filho (2006). A Constituição da República dos Estados Unidos do Brasil de 1934 fez inserir o tema da causa indígena na ordem constitucional, com a garantia da posse das terras onde as comunidades estivessem permanentemente localizadas.

Essas disposições foram reproduzidas nos textos constitucionais de 1937 (artigo 129) e 1946 (artigo 216), em que a causa indígena continuou cingida, basicamente, ao reconhecimento da posse sobre as terras tradicionalmente ocupadas, com fundamento no instituto do indigenato, um direito congênito e primário que independe de título ou reconhecimento formal. A Constituição do Brasil de 1967, alterada pela Emenda Constitucional de 1969, passou a considerar as terras ocupadas pelos povos indígenas como patrimônio da União. (SANTOS FILHO, 2006)

No panorama constitucional anterior, todavia, o paradigma da assimilação, integração ou provisoriedade da condição indígena permaneceu irradiando seus postulados na ordem jurídica, até que a Constituição da República Federativa do Brasil de 1988 trouxe novos ares. Segundo Souza Filho (2013), somente então, depois de praticamente quinhentos anos de contato, ocorreu a ruptura com o ideário assimilador e se estabeleceu uma nova relação entre o Estado nacional e as comunidades indígenas habitantes de seu território.

Agora, no contexto socioeconômico da ordem constitucional brasileira, estabeleceu-se o paradigma da interação, fundamentado no respeito à diferença. Para Barreto (2006), o índio foi reconhecido como diferente, mas sem confundir diferença com incapacidade, até porque também lhe confere a capacidade para ingressar em juízo na defesa de seus direitos, 
independentemente de intermediação. Assim, assentou-se uma tutela protetiva de patamar constitucional, a salvo de ataques pela via do processo legislativo ordinário.

O Supremo Tribunal Federal (2009), ao julgar o emblemático Caso Raposa Serra do Sol, embora tenha se utilizado da terminologia própria do pensamento integracionista, destacou a conotação plural do vocábulo índios, que exprime as numerosas etnias e a diversidade indígena tanto interétnica quanto intraétnica, e assentou que os índios em processo de aculturação permanecem índios para o fim de proteção constitucional, não limitada aos silvícolas, "ainda em primitivo estádio de habitantes da selva".

Souza Filho (2013) destaca que a Constituição reconheceu aos índios, de um lado, o direito à sociodiversidade, de cunho coletivo universal, e, de outro, o direito à existência das próprias comunidades, também de caráter coletivo, que se revela em três dimensões interligadas, que englobam direitos territoriais, direitos de organização social e direitos culturais. A íntima ligação entre essas dimensões faz com que eventual violação a uma delas também afete as demais.

O direito de todos à existência e manutenção dos diversos povos e suas culturas traduz uma obrigação de cada povo e cada Estado ao respeito pelo outro, presente na ordem internacional e, de forma cada vez mais explícita, nas constituições nacionais. Esse direito à alteridade possui estreita relação com o direito à biodiversidade, não só porque as culturas dependem do ambiente, mas também em decorrência dos conhecimentos tradicionais inerentes à diversidade social.

O direito à existência dos próprios povos, por sua vez, não se confunde com a soma de direitos individuais, pois pertence a um grupo sem pertencer a ninguém em especial, tendo como sujeito cada povo determinado, com caracteres inalienáveis, imprescritíveis, impenhoráveis e intransferíveis. Assim, cada um é obrigado e tem o dever de promover a sua defesa, que beneficia a todos. Tratando-se de direito indivisível entre seus titulares, mesmo uma eventual divisão do objeto faria com que todos os titulares do todo permanecessem titulares das partes.

A leitura conjugada dos dispositivos que versam sobre a causa indígena (artigos $231 \mathrm{e}$ 232), meio ambiente (artigo 225), cultura (artigos 215, 216 e 216-A) e atividade econômica (artigos 170 a 181), permite identificar, na ordem socioeconômica da atual Constituição Federal brasileira, uma efetiva mudança de paradigma na tutela de bens comuns, verificada em várias frentes, das quais este estudo destacará o respeito à alteridade das comunidades 
indígenas, assentado no reconhecimento do direito de preservar as peculiaridades de sua organização social e de sua própria cultura, que abrange costumes, línguas, crenças e tradições.

Os conhecimentos tradicionais ou saberes adquiridos pela hereditariedade e práticas comuns, em que se inserem os saberes indígenas, têm sido albergados no conjunto substancial da cultura brasileira, na qual, conforme Molinaro e Dantas (2013), também se engloba o complexo de arquétipos do comportamento, das crenças, dos costumes e demais particularidades que distinguem os diversos grupos que formatam a comunidade nacional e, portanto, constituem o patrimônio cultural brasileiro.

Ademais, a concepção unitária de meio ambiente, que conjuga os enunciados normativos constitucionais de proteção ao meio ambiente biológico e cultural, denota que os bens ambientais podem ser visualizados como gênero de que são espécies os bens naturais e os culturais. Conforme Santilli (2005), a interface entre aspectos biológicos e socioculturais do meio ambiente, assim conjugados, estabelece as bases do paradigma socioambiental do desenvolvimento sustentável. Os saberes indígenas certamente se inserem nessa concepção de meio ambiente.

As pretensões econômicas que buscam legitimar a utilização dos saberes indígenas na atividade bioindustrial, portanto, encontram entraves num contexto maior de proteção socioambiental, que se irradia tanto na ordem socioeconômica como nos direitos e garantias individuais, fazendo com que se sobreleve a função socioambiental da propriedade, tanto no contexto do direito de propriedade intelectual (artigo $5^{\circ}$, XXII e XXIII) quanto no conjunto de princípios da ordem econômica (artigo 170, II e III).

Existem importantes objeções (RÊGO, 2012), no sentido de que o direito de propriedade intelectual funciona como instrumento de garantia da expropriação realizada pelas empresas transnacionais, as quais se servem livremente dos tesouros da diversidade genética para transformá-los em produtos vendidos a altos preços, depois de levemente alterados e patenteados, apropriando-se, assim, de algo que foi livremente partilhado e comercializado entre agricultores e camponeses ao longo da história da humanidade.

Sem embargo, com base na ideia de que direitos fundamentais não possuem caráter absoluto, buscar-se-á uma conciliação do âmbito de incidência das normas jusfundamentais em aparente conflito, a fim de projetar um possível sistema sui generis de proteção à propriedade intelectual, nos casos em que se integrem saberes indígenas, sem descuidar do 
necessário resguardo da cultura dos povos milenares brasileiros, numa espécie de ponderação entre direitos coletivos e individuais.

Os recursos naturais e conhecimentos tradicionais associados estão em constante erosão, ao passo que as demandas sociais se fazem cada vez maiores, seja no contexto da indústria agrícola e alimentar ou da indústria médica e farmacológica. Parece razoável permitir o acesso à sabedoria indígena para beneficiar a própria coletividade, efetivando os ideais de solidariedade. Ao mesmo tempo, isso significaria evidente redução de tempo e gastos com pesquisas, com otimização da atividade econômica.

A magnitude dos direitos comuns envolvidos no embate de interesses, portanto, conferelhes certa precedência em relação aos interesses individuais aparentemente contrapostos. Logo, na ponderação entre a seara socioambiental em que se inserem os saberes indígenas e a esfera individual em que se posiciona o direito de propriedade intelectual, a prevalência dos direitos dos povos indígenas recomenda a conformação, ou limitação externa, desse último direito, até mesmo como forma de efetivar sua função socioambiental.

O Supremo Tribunal Federal (2005), quando se pronunciou sobre o conflito entre valores inerentes ao meio ambiente e à atividade econômica, posicionou-se no sentido de que a preservação da integridade do meio ambiente constitui expressão constitucional de um direito fundamental que assiste à generalidade das pessoas, de tal forma que a atividade econômica não pode ser exercida em desarmonia com os princípios destinados a tornar efetiva a proteção ao meio ambiente:

\begin{abstract}
A incolumidade do meio ambiente não pode ser comprometida por interesses empresariais nem ficar dependente de motivações de índole meramente econômica, ainda mais se se tiver presente que a atividade econômica, considerada a disciplina constitucional que a rege, está subordinada, dentre outros princípios gerais, àquele que privilegia a "defesa do meio ambiente" $(\mathrm{CF}$, art. 170, VI), que traduz conceito amplo e abrangente das noções de meio ambiente natural, de meio ambiente cultural, de meio ambiente artificial (espaço urbano) e de meio ambiente laboral. Doutrina. Os instrumentos jurídicos de caráter legal e de natureza constitucional objetivam viabilizar a tutela efetiva do meio ambiente, para que não se alterem as propriedades e os atributos que lhe são inerentes, o que provocaria inaceitável comprometimento da saúde, segurança, cultura, trabalho e bem-estar da população, além de causar graves danos ecológicos ao patrimônio ambiental, considerado este em seu aspecto físico ou natural.
\end{abstract}

Assim, o direito de propriedade intelectual poderia bem servir de âmbito de regulação das projeções econômicas inerentes à captação e integração dos saberes indígenas às tecnologias bioindustriais. Contudo, os inventos recobertos com a exclusividade da patente devem submeter-se a algumas condições especiais para que não ocorra exatamente aquilo que 
se tem constatado na prática da biopirataria, que vem assegurando aos usurpadores da sabedoria indígena a exclusividade sobre os proveitos dessa criação intelectual.

Nesse contexto, a proposta do Protocolo de Nagoya constitui uma alternativa razoável de condicionamento do acesso. O consentimento prévio informado permitiria aos próprios povos indígenas deliberar sobre os saberes cujo acesso lhes interesse franquear, ao passo que o ajuste mútuo apresenta a flexibilidade necessária para compatibilizar as tratativas de acordo com o pluralismo jurídico e a diversidade cultural das comunidades, sem excluir a possibilidade de mediação estatal. A repartição de benefícios, por fim, possibilitaria uma contrapartida aos originários detentores do conhecimento tradicional associado.

O papel da Constituição Federal de 1988, acaso se pretenda extrair de seu texto a efetividade da tutela dos bens comuns envolvidos, de viés socioambiental, caracteriza-se pelo protagonismo na proteção dos saberes indígenas, seguindo os postulados da Convenção da Diversidade Biológica e do Protocolo de Nagoya. Em seu roteiro, constam a regulação do acesso aos conhecimentos tradicionais associados por meio do consentimento prévio informado, dos termos mutuamente acordados e do acesso e repartição de benefícios.

\section{CONSIDERAÇÕES FINAIS}

Os povos indígenas brasileiros, nos últimos cinco séculos, foram subjugados por meio de um processo de colonização que lhes expropriou terras e recursos naturais. Numa versão neocolonialista, essa expropriação também tem se direcionado aos saberes milenares cultivados pelas comunidades originárias do Brasil, por meio da prática da biopirataria dos recursos tangíveis da biodiversidade e dos intangíveis conhecimentos tradicionais associados, conservados por esses povos desde remotos tempos pré-colombianos, em línguas próprias.

O movimento colonizador atuou não só na frente econômica da expropriação de terras e riquezas, mas também como um processo de aculturação pautado pelos padrões civilizatórios europeus. Esse processou desencadeou-se pelo aparato da Coroa portuguesa, conjugado ao da Igreja, impondo um massacre étnico - pela cruz e pela espada - que por pouco não dizimou as comunidades que, há pelo menos doze milênios, habitam o território e cultivam seus traços culturais ao longo das gerações.

A versão atual da biopirataria, além da expropriação de riquezas naturais, também se apropria do patrimônio cultural dos povos indígenas, a exemplo do caso Ayahuasca, que resultou em anos de proveitos econômicos legitimados pelo direito de propriedade intelectual 
de um suposto invento patenteado por quem, na verdade, captou um saber milenar dos povos indígenas amazônicos, ligado à própria espiritualidade dos originários criadores da bebida extraída da flora amazônica.

$\mathrm{Na}$ órbita internacional, a Organização Mundial da Propriedade Intelectual e a Organização Mundial do Comércio não oferecem óbices a práticas como a ilustrada nesse caso, mas a Convenção sobre Diversidade Biológica e a Declaração das Nações Unidas sobre os Direitos dos Povos Indígenas consolidam normas que contribuem para a tutela dos interesses dos povos indígenas, com destaque para o Protocolo de Nagoya, que protege os recursos da biodiversidade e os conhecimentos tradicionais associados, condicionando o acesso ao consentimento prévio informado, aos termos mutuamente acordados e à repartição de benefícios.

A Constituição da República Federativa do Brasil de 1988, nas disposições acerca da ordem socioeconômica, congloba um conjunto de normas que tutelam os saberes indígenas, mesmo diante da proteção jusfundamental que reserva ao direito de propriedade intelectual, que deve atender à função socioambiental. Assim, num conflito de normas, a precedência dos interesses socioambientais em que se inserem os conhecimentos tradicionais dos índios deve consolidar-se frente aos direitos de cunho individual contrapostos.

Enfim, a maior conclusão deste estudo consiste na constatação da necessidade de reconhecer efetivamente a cultura dos povos indígenas brasileiros, preservando a identidade de seus saberes. O combate à biopirataria emerge como instrumento para evitar que falsários da propriedade intelectual vendam como suas criações que fazem parte da cultura milenar perpetuada ao longo de sucessivas gerações, num cenário que coloca a Constituição, e o próprio Estado brasileiro, como protagonistas da tutela dos bens comuns.

Até mesmo para assegurar sua própria soberania, o Brasil deve garantir que o acesso aos saberes indígenas seja precedido de consentimento prévio informado das respectivas comunidades afetadas, com ajuste mútuo da extensão do acesso, bem como com a justa e equitativa repartição de benefícios, que não deve se confundir com a mera retribuição econômica, mas sobretudo velar pelo reconhecimento da origem dos conhecimentos e acesso aos resultados tecnológicos obtidos.

\section{REFERÊNCIAS}

BARBIERI, Sami Roges Jordy. Biopirataria e povos indígenas. São Paulo: Almedina, 2014. 
BARBOSA, Marco Antonio. Direito antropológico e terras indígenas no Brasil. São Paulo: Plêiade, 2001.

BARRETO, Helder Girão. Direitos indígenas: vetores constitucionais. Curitiba: Juruá, 2006.

BRASIL. Constituição da República Federativa do Brasil de 1988. Brasília, DF, 05 out. 1988. Disponível em: <http://www.planalto.gov.br/ccivil_03/Constituicao/Constituicao. htm>. Acesso em: 03 jul. 2014.

Constituição da República dos Estados Unidos do Brasil de 1934. Disponível em: <http://www.planalto.gov.br/ccivil_03/Constituicao/Constituicao34.htm>. Acesso em: 03 jul. 2014.

Lei 13.123, de 20 de maio de 2015. Regulamenta o inciso II do $\S 1^{o}$ e o $\$ 4^{\underline{o}}$ do art. 225 da Constituição Federal, o Artigo 1, a alínea j do Artigo 8, a alínea c do Artigo 10, o Artigo 15 e os $\$ \S 3^{\circ}$ e $4^{o}$ do Artigo 16 da Convenção sobre Diversidade Biológica, promulgada pelo Decreto $n^{\circ}$ 2.519, de 16 de março de 1998; dispõe sobre o acesso ao patrimônio genético, sobre a proteção e o acesso ao conhecimento tradicional associado e sobre a repartição de benefícios para conservação e uso sustentável da biodiversidade; revoga a Medida Provisória ñ 2.186-16, de 23 de agosto de 2001; e dá outras providências. Disponível em: <http://www.planalto.gov.br/CCIVIL_03/_Ato2015-

2018/2015/Lei/L13123.htm>. Acesso em: 21 mai. 2015.

. Medida Provisória 2.186-16, de 23 de agosto de 2001. Disponível em:

<https://www.planalto.gov.br/ccivil_03/MPV/2186-16.htm>. Acesso em: 08 jan. 2015.

. MSC 245/2015 - Mensagem de Acordos, convênios, tratados e atos internacionais.

Disponível em:

<http://www.camara.gov.br/proposicoesWeb/fichadetramitacao?idProposicao=547397>.

Acesso em: 18 mai. 2015.

BASSO, Maristela. Propriedade intelectual na era pós-OMC. Porto Alegre: Livraria do Advogado, 2005.

COLAÇO, Thais Luzia. O despertar da Antropologia Jurídica.In: COLAÇO, Thais Luzia (org.). Elementos de Antropologia Jurídica. 2. ed. São Paulo: Conceito, 2011.

CONVENÇÃO SOBRE DIVERSIDADE BIOLÓGICA. Disponível em: <http://www.mma.gov.br/estruturas/sbf_dpg/_arquivos/cdbport.pdf > Acesso em: 10 de fev. 2015 .

COSTA, Fernanda Bianco de Lucena. O Protocolo de Nagoya e o quadro legislativo brasileiro de acesso aos recursos genéticos. In: Revista do Instituto do Direito Brasileiro, ano 2 (2013), n. 11, p. 12213-12274.Disponível em: <http://www.idbfdul.com/uploaded/files/2013_11_12213_12274.pdf>. Acesso em: 08 jan. 2015. 
CUNHA, Manuela Carneiro. Índios no Brasil: história, direitos e cidadania. São Paulo: Claro Enigma, 2012.

\section{DECLARAÇÃO DAS NAÇÕES UNIDAS SOBRE OS DIREITOS DOS POVOS}

INDÍGENAS. Disponível em:

<http://www.un.org/esa/socdev/unpfii/documents/DRIPS_pt.pdf>. Acesso em: 10 ago. 2015.

FURTADO, Celso. Formação econômica do Brasil.18. ed. São Paulo: Editora Nacional, 1982.

GILL, Richard T. Introdução ao desenvolvimento económico. Trad. de Maria Luiza Vaz Pinto. 2. ed. Lisboa: Clássica Editora, 1972.

GOMES, Mércio Pereira. Os índios e o Brasil: passado, presente e futuro. São Paulo: Contexto, 2012.

HUBERMAN, Leo. História da riqueza do homem. Trad. de Waltensir Dutra. 13. ed. Rio de Janeiro: Zahar Editores, 1977.

IACOMINI, Vanessa. Biodireito e o combate à biopirataria. Curitiba: Juruá, 2009.

LIMA, Salomão Loureiro de Barros. Biopirataria e propriedade intelectual: a proteção da biodiversidade brasileira. Maceió: Edufal, 2013.

MOLINARO, Carlos Alberto; DANTAS, Fernando Antonio de Carvalho. Da Cultura. In: CANOTILHO, José Joaquim Gomes; MENDES, Gilmar Ferreira; SARLET, Ingo Wolfgang; STRECK, Lenio Luiz (coord. científica). Comentários à Constituição do Brasil. São Paulo: Saraiva, 2013.

PEREIRA, Ana Cristina Paulo. A proteção patentária interna e internacional: implicações do Acordo TRIPS/OMC na ordem jurídica brasileira. Rio de Janeiro: Lumen Juris, 2009.

PROTOCOLO DE NAGOYA. Disponível em: <http://www.cbd.int/abs/doc/protocol/nagoyaprotocol-es.pdf>. Acesso em: 05 jan. 2015.

RÊGO, Patrícia de Amorim. Biodiversidade e repartição de benefícios. Curitiba: Juruá, 2012.

RIBEIRO, Darcy. O povo brasileiro: a formação e o sentido do Brasil. 3. ed. São Paulo: Companhia das Letras, 1995.

SANTILLI, Juliana. Socioambientalismo e novos direitos: proteção jurídica à diversidade biológica e cultural. São Paulo: Peirópolis, 2005.

SANTOS FILHO, Roberto Lemos dos. Apontamentos sobre o direito indigenista. Curitiba: Juruá, 2006. 
SOUZA FILHO, Carlos Frederico Marés de. Dos índios. In: CANOTILHO, José Joaquim Gomes; MENDES, Gilmar Ferreira; SARLET, Ingo Wolfgang; STRECK, Lenio Luiz (coord. científica). Comentários à Constituição do Brasil. São Paulo: Saraiva, 2013.

SUPREMO TRIBUNAL FEDERAL. ADI 3540 MC, Rel. Min. Celso de Mello, Tribunal Pleno, julgado em 01 set. 2005. Disponível em:

$<$ http://redir.stf.jus.br/paginadorpub/paginador.jsp?docTP=AC\&docID=387260>. Acesso em: 05 jun. 2015.

Pet 3388, Rel. Min. Carlos Britto, Tribunal Pleno, julgado em 19 mar. 2009.

Disponível em:

$<$ http://redir.stf.jus.br/paginadorpub/paginador.jsp?docTP=AC\&docID=630133>. Acesso em: 05 jun. 2015.

TOLEDO, André de Paiva. Brasil: Marco da Biodiversidade é contrário aos interesses nacionais. Entrevista especial com André de Paiva Toledo. Disponível em: <http://www.biodiversidadla.org/Portada_Principal/Documentos/Brasil_Marco_da_Biodi versidade_e_contrario_aos_interesses_nacionais._Entrevista_especial_com_Andre_de_Paiva_ Toledo>. Acesso em: 05 jun. 2015. 